\title{
Mass Media and Social Media Impact on Health Literacy And Patient Empowerment of Diabetic Patients
}

\section{Sarah Ahmed Fouad}

The American University in Cairo School of Global Affairs and Public Policy

Ahmed Taher ( $\nabla$ ataher@aucegypt.edu )

American University in Cairo https://orcid.org/0000-0001-6915-003X

Ingy Shafei

Flinders University of South Australia: Flinders University

Research article

Keywords: diabetic patient's, empowerment, online literacy

Posted Date: January 22nd, 2021

DOI: https://doi.org/10.21203/rs.3.rs-151823/v1

License: (c) (i) This work is licensed under a Creative Commons Attribution 4.0 International License.

Read Full License 


\section{Abstract}

This research assesses the role of health literacy in diabetic patient's lifestyle modification and disease management as a form of patient empowerment. The study evaluated health literacy, patient empowerment, and sources of information for diabetic patients. The research utilized a quantitative methodology using purposive sampling for 408 diabetic patients in diabetes institutes and online social media platforms addressing diabetic patients. The study included two phases, offline and online, with comparisons of online versus offline diabetic literacy. A conceptual model assessing the role of health literacy in diabetic patient's lifestyle modification and disease management as a form of patient empowerment was developed. The research will contribute to diabetic patient's health literacy, promotion of creating social network models, educational and patient support initiatives, online literacy, and effective diabetic self-managers.

\section{Introduction}

The negative consequences of diabetes mismanagement do not affect the patient alone; but also the patients' caregivers, the community, and the healthcare system, thereby causing global economic and social adverse effects. Diabetic patients are at higher risk of developing a number of incapacitating health problems; including high blood glucose levels, cardiovascular disease, blindness, kidney failure, and lower-limb amputation (International Diabetes Federation, 2019).

When it comes to diabetes control, it is not limited only to the anti-diabetic therapy, yet it requires managing the patient's overall lifestyle which relies to a great extent on the patients' own motivation and self-care. Therapeutic education plays an important role and works at 'knowing', 'doing', and 'being'. The role of relevant educational programs in response to patients' needs is essential in the success of treatment (Baudrant et al., 2007). Lubi (2019) confirmed that individuals suffering from chronic illnesses prefer maintaining their current lifestyles and are willing to look for relevant information, which is also related to the duration and severity of their illness.

In the case of diabetic patients, low levels of patient awareness on diabetes and its complications are generally associated with a higher risk of complications and bad disease prognosis. The decreased patient awareness is in turn associated with a lack of information, financial constraints, and lower education levels. Health illiteracy and misconceptions about diabetes are common. Abueleinen et al. (2011) has found that $35 \%$ identified the internist as the primary source of information on advanced diabetic eye disease; almost $9 \%$ identified media while only 3.5\% selected reading printed materials as their main source of information on diabetic retinopathy.

Mass media can be an invaluable tool in reaching a large sector of the population and providing educational and awareness programs and campaigns via radio and visual media. The Internet serves as a platform that provides access to enormous amounts of data and a primary 'turn-to' hub for the patient. In fact, sometimes the Internet represents a competition with the clinician; simply using a few keywords 
to search for the symptoms of the disease can direct the patient to hundreds of websites discussing healthcare information (Gordon, 2011). The predicament here lies in the kind of content that the patient may access -in terms of level, quality, or trustworthiness, as the quality and appropriateness of information of the websites for patients are not evaluated or ranked. Unfortunately, patients may feel that the physician's advice is outdated or contradicts the information available online. For better or worse, celebrities' experiences or nontraditional approaches shared online may not be that effective (Gordon, 2011).

\section{Health literacy and patient empowerment}

Shulz and Nakamoto (2013a) reviewed the health behavior literature and found that health literacy and patient empowerment were the two related but distinct concepts driving health-related behaviors, affecting patient communication outcomes, healthcare costs, and public health efforts. Since the goal of patient empowerment is self-sufficiency and self-efficacy, health literacy is a foundational key factor in helping the patients become less dependent. Accordingly increased health literacy is not just increased information provision. Self-care and analyzing educational needs play an important role.

In mass media campaigns exposure to medical or educational messages is generally passive. The penetration of digital platforms and social media (SM) in the hunt for medical information has made for active autonomous involvement of the patient in her healthcare clear and prominent. However, this active autonomous involvement can be delusional. The search or adopting medicinal information can be shaped by patient biases, preferences, ignorance, and commercial directions. Patient empowerment should include factual knowledge, how-to knowledge, and judgment skills allowing patients to link the knowledge to personal goals (Shulz \& Nakamoto, 2013b).

\section{Health literacy}

The concept of health literacy first appeared in 1974 in the US, where research advocated reaching minimal health education standards (Shulz \& Nakamoto, 2013a). Ever since, health literacy is defined depending on the context in which it is used (Berkman et al., 2010). Starting from the functional literacy of healthcare in terms of 'people's ability to read and understand written information' and expanding to include 'the personal and relational factors that affect a person's ability to acquire understand and use information about health and health services' (Batterham et al., 2016).

Camerini et al. (2012) have found a significant body of literature supporting the relationship between lower levels of health literacy and a 'poorer' health status, in terms of disease knowledge and management, use of health resources. There was a strong association between inadequate health literacy and poor compliance rates, increased hospitalizations, increased health costs, and general inefficient use of healthcare services. These results support the notion that 'Health literacy' is a multidimensional concept that impacts health-related behavior in a broader manner than simply the functional and numerical literacy of patients. 
Health literacy is not meant to replace professional medical support. The goal of health literacy as an enabler in health decision making and grounded judgments such as; the capability of explaining the healthcare problem, to seek help, and to ask for changing or stopping a treatment protocol. Health literacy is expected to lead to improved health outcomes and physical wellbeing, and limit the actions or beliefs that impact health status negatively. (Shulz \& Nakamoto, 2013a). Sarkar et al (2010) advocated involving patients with low health literacy and low access to internet-based services as part of the design of effective healthcare communication.

Nutbeam (2000) has three tiers for health literacy; the functional/basic literacy, the communicative/interactive literacy, and finally the critical literacy. The first tier is the basic level of literacy and functions through the transmission of factual information. The second tier, which involves building the skills and confidence needed by patients to continue in their journey, implement the health knowledge in daily practice and raise community acceptance and support to patients. Communicative literacy is best accomplished through personal communication and education. For achieving health literacy, Nutbeam (2000) advocated critical literacy which includes the ability to critically analyze and use the information to participate in actions that overcome structural barriers to health.

Batterham et al. (2016) presented six levels of health literacy assessment depending on the health service setting and the corresponding measurement purposes. The first level was the individual patients, and the main purpose of measuring health literacy for this group was to solve complex problems for patients. The second level of health literacy assessment was patient groups with the purpose of recognizing common contributing factors. The third health service setting to be assessed was individual health services aiming to create responding strategies. The fourth level was the assessment of involved local areas aiming to plan appropriate marketing and education strategies. The fifth level of health literacy assessment was national surveys comparing regions and groups across the same country.

Finally, the sixth level of health literacy assessment is used to develop international comparisons among countries to define role model countries that succeeded in improving health literacy and trying to adopt these models in countries with systemic low literacy.

It is important to measure the components of health literacy in order to assess the actualization of its objectives and purposes. The limitations of tools measuring only the 'reading, comprehension and numeracy skills, and cognitive tasks' overlooks the broader picture covered by modern definitions of health literacy. The Ophelia (Optimizing Health Literacy and Access) approach offers multidimensional health literacy measurement tools such as; the Health Literacy Questionnaire (HLQ) (Batterham et al., 2016).

Osborne et al. (2013) conceptualized, developed, and tested the Health Literacy Questionnaire (HLQ). It examines nine separate and distinct health literacy variables that reflect an individual's competencies and experiences when attempting to engage with health practitioners and services. The nine generated variables resulted from amalgamating responses and opinions from the general population, patients, healthcare professionals, and policymakers. Through rigorous development and testing, Osborne et al. 
(2013) indicated that nine distinct variables were conceptually robust, valid with good to excellent psychometric properties. Osborne et al. (2013) also defined the low and high descriptors of each variable on the HLQ they built in order to provide measurable data for each variable. In addition, Osborne et al. (2013) linked Nutbeam's three tiers definition to the HLQ constructs and their corresponding scales, with expected elements of overlap emerging.

Batterham et al. (2016) have also explored the individual variations in two patient profiles using HLQ. If the nine variables of the HLQ tested in these two patients are evaluated as an average single score, the results will show that both patients have similar health literacy needs. However, upon examining all of the nine variables in each profile as distinct scores, the HLQ results provide a comprehensive overview of each profile that uncovers different health literacy needs for each patient.

For patients with long-term conditions, including diabetes, Friis et al. (2016) aimed at quantifying the levels of health literacy and compare this with levels of the general population. Using two variables from HLQ; "Ability to understand health information" and "Ability to actively engage with healthcare providers", in their survey, Friis et al. $(2016)$ had surveyed $(n=29473)$ in the Central Denmark Region. Patients with long-term conditions demonstrated a higher rate of difficulties in understanding and engagement with healthcare providers. Variations among disease groups emerged, with cancer patients facing fewer difficulties and mental health disorders and patients with more than one long-term condition demonstrating higher difficulties in engagements with healthcare providers. Lower education was also associated with lower levels of health literacy. Health literacy problems are manifested in some examples of consumer behavior such as demanding inappropriate medication as well as reduced adherence and even discontinuation of therapeutics (Osborne et al., 2016).

Extending the concept of health literacy to include the capabilities and resources required for individuals to conceptualize the e-health literacy Framework was the focus of Norgaard et al., (2015). Through using concept mapping to generate a comprehensive model of e-health literacy, Norgaard et al., (2015) carried out eight concept mapping workshops in Denmark and UK with patients and healthcare professionals to deduce the key insights and statements needed to form the e-health literacy Framework. The result of the concept mapping in these eight workshops yielded generated 450 statements by patients and healthcare professionals, the 450 statements were separated into 128 clusters. These clusters were categorized under 7 main domains that form the e-health literacy framework (eHLF) as follows: '1. Ability to process information, 2. Engagement in own health, 3. Ability to engage actively with digital services, 4. Feeling safe and in control, 5. Motivation to engage with digital services, 6 . Having access to systems that work, and 7. Digital services that suit individual needs'.

\section{Patient empowerment}

Empowerment is the process by which people gain mastery over their lives. Empowerment is a common concept among several disciplines that intersect in explaining how for people to improve the quality of lives both in the workplace and at home, they should be able and motivated to bring about changes, not only in their personal behavior but also in their social situations and the organizations that influence their 
lives (Shulz \& Nakamoto, 2013a). 'Accordingly, empowerment is a relational construct (e.g. in the doctorpatient consultation) associated with the concepts of power, equity, and control of situations, and thus implies a capacity to solve problems and get a fair share of resources' (Shulz \& Nakamoto, 2013a).

Anderson and Funnell (2010) have argued that empowerment is both a process and an outcome. Empowerment is a process when the purpose of an educational intervention is to increase one's ability to think critically and act autonomously. Empowerment is an outcome when an enhanced sense of selfefficacy occurs as .a result of the process. As such, when empowerment is considered an outcome, it's not regarded as a present or absent variable, however, it is regarded as a continuous variable that can have incremental increases or decreases.

Camerini et al. (2012) presented the health empowerment as a multidimensional construct that covers self-esteem, self-efficacy, competency, locus of control, and other traditional psychological constructs. The profile of an empowered patient is described by Shulz \& Nakamoto (2013a) as a patient who is not a passive receiver of information and advice. She actively seeks information, processes it, and tries to understand and extract meaning relevant to her condition. Then this empowered patient chooses and enacts behaviors she concludes is appropriate to the present health situation.

Shulz and Nakamoto (2013a) presented the operationalization of healthcare patient empowerment by breaking the construct down into four concepts; meaningfulness (or relevance), self-efficacy (or competence), self-determination (or choice), and impact. Focusing on patient empowerment as a concept presents the patient as an autonomous actor, responsible, and involved actively in decision-making regarding his or her health (Shulz \& Nakamoto, 2013a). 'The operationalization of empowerment described above aims more clearly at measuring the state than the process of empowerment. As measures of health literacy move to capture condition-specific knowledge, the issue arises whether condition-specific measures of empowerment are necessary. If empowerment aims at mastery over one's life and health management, it can be assumed that it takes different forms for chronic and acute conditions, or for life-threatening and less severe conditions'.

Shulz and Nakamoto (2013a) have also agreed with Anderson and Funnell (2010) on the proposal that empowerment is a process and an outcome, and listed seven fundamental principles of empowerment. The researcher added the seven fundamental principles of patient empowerment (Anderson \& Funnell, 2010) to the patient empowerment constructs developed by Shulz and Nakamoto (2013a).

\section{Health Outcomes}

Patients' willingness to be more involved in health care decisions does not necessarily mean that the patients are experts but it means that they are more empowered. The main constituents of the concept of health literacy are knowledge and the ability to utilize this knowledge, but knowledge alone is not enough to make people more involved (Shulz \& Nakamoto, 2013b). Worth mentioning is that the operationalization of both concepts distinguishes between empowerment and literacy highlighting what is involved in the empowerment process and can be classified as subjective factors. 
Shulz \& Nakamoto (2013b) have also provided an example of how direct-to-consumer advertising (allowed only in the U.S. and New Zealand) advocates the patient to ask their physician if the promoted medications are suitable for them. Upon assessing the patient's response to a print advertisement for a medication, the patients were very confused about the product claims; however, they sought medical advice from their physicians. These results support the argument that direct-to-consumer medical advertisements leverage patient empowerment further more than they leverage health literacy. Patients are not educated about the advertised medication, its expected course of treatment, or its adverse effects; however, they are urged to ask their physician for this advertised medication in response to the ad.

In a matrix combing the patient profiles considering the levels of the two concepts health literacy and psychological patient empowerment, four profiles adapted from Shulz and Nakamoto (2013b) include, the needlessly dependent patient, the high needs patient, the dangerous self-manager, and the effective self-manager. Camerini et al. (2012) pointed out that both health literacy and patient empowerment can simultaneously affect health outcomes. Although the presence of knowledge is not necessarily considered a motivating force of change, both health literacy and patient empowerment can leverage the patient's self-management and accordingly the health outcomes.

According to Shulz and Nakamoto (2013b), empowering patient programs presume knowledge, while health literacy literature regularly looks to empowerment as a goal but assumes that high levels of expertise will result in involvement and self-management. Consequently, Shulz and Nakamoto (2013a) considered that health literacy is the linchpin for patient empowerment and this part will be the focus of the hypotheses in this research.

\section{Methods}

The purpose of this research is to assess the role of health literacy and patient empowerment in Egyptian diabetic patient's lifestyle modification and disease management. The study will seek to evaluate the health literacy levels of diabetic patients, investigate the levels of diabetic patient empowerment, and identify main sources of information for diabetic patients.

\section{Theoretical Grounding: Bandura's Social Cognitive Theory}

Diabetic patients' health literacy and empowerment were examined in his paper to assess the effect of disease knowledge and literacy on diabetes management levels in diabetic patients. The research was guided by Bandura's $(1998,2004)$ social cognitive theory which incorporates studying the interactions among the learner, the behavior patterns, and the environment. The social cognitive theory incorporates the interactions among the learner, the behavior patterns, and the environment with more emphasis on the learner. The theory provides a framework that examines the causes and tools of media that affect people's learning, thoughts, emotions, and behavior, explaining this social and psychological function in terms of triadic (personal, behavioral, and environmental causes) joint (bidirectional) causation instead of unidirectional causation (Bryant \& Oliver, 2009). The learner as denoted by Bandura is in the heart of 
the social cognitive theory, which reflects on the need to identify the issues that affect the learner in social situations and how the learner responds. In the current research, understanding the learner's needs in diabetes management and assessing the current literacy and patient empowerment levels, is the first step to develop successful patient care programs and sustained educational initiatives.

\section{Research conceptual model}

This research's conceptual model (Fig. 1) assumes the certain relationships between the independent variables manifested in the scales of health literacy and the dependent variables that constitute the patient empowerment based on the findings of Shulz and Nakamoto (2013a).

\section{Hypotheses}

Based on the review of the literature, seven hypotheses were formulated to assess the role of health literacy and patient empowerment in Egyptian diabetic patient's lifestyle modification and disease management, both in an online as well as a face-to-face setting. The hypotheses are:

\section{Hypothesis 1}

The more the diabetic patient has sufficient information to manage diabetes, the more the diabetic patient can find meaningfulness in the actions they do on daily basis.

\section{Hypothesis 2}

The higher the ability of the diabetic patient to find good quality health information on diabetes, the more the patient is self-determined and can choose between different ways of diabetes management.

\section{Hypothesis 3}

The more the diabetic patient understands health information on diabetes well enough to know what to do, the more self-efficacy he/she has in diabetes management.

\section{Hypothesis 4}

The higher the ability the diabetic patients have to actively engage with healthcare providers, the more self-efficacy he/she has in diabetes management.

\section{Hypothesis 5}

The higher the diabetic patient actively manages his/her diabetes, the higher the positive impact on his/her diabetes management.

\section{Hypothesis 6}


Diabetic patients who complete the online survey are more likely to have higher levels of Health literacy than diabetic patients who respond to the offline self-administered survey.

\section{Hypothesis 7}

Diabetic patients who complete the online survey are more likely to have higher levels of patient empowerment than diabetic patients who respond to the offline self-administered survey.

\section{Questionnaire design}

The survey was designed to test the research hypothesis and comprised of four sections shuffling the research themes to avoid respondent bias and reactivity. The survey was designed to be used both as an online survey and a self-administered (face to face - offline) survey. The survey questions were founded on health literacy questionnaire (HLQ) items after obtaining the license agreement from the original authors (Osborne et al. 2013), and the four concepts under patient empowerment (self-efficacy, selfdetermination, meaningfulness, and impact). All the main constructs were measured using multi-item 5point Likert scales of the HLQ (Osborne et al., 2013) as explained before. Other demographic and screening questions were developed as appropriate. Data were collected face-to-face and online simultaneously. The survey aimed to address the component objectives of measuring three levels of diabetic patients' health literacy and levels of patient empowerment and determining the sources of information for the Egyptian diabetic patient especially the online sources of information.

\section{Population}

A population of Egyptian diabetic patients older than 18 years in the National Institute of Diabetes and Endocrinology (NIDE) and online social media platforms "Facebook" were surveyed in the study. The authors acquired access to the NIDE where a large population of diabetic patients from low to medium socioeconomic classes and different educational backgrounds. The authors selected Arabic online groups dedicated and created by diabetic patients for diabetes management on Facebook. These groups had thousands of diabetic patients utilizing social media and online sources of information and data as key sources in their daily diabetes management. The target sample size was 400 respondents from both groups.

\section{Sampling and data gathering}

After screening for age, random sampling was used in the current research to enable the researchers to collect data from Egyptian diabetic patients older than 18 years old. Access to groups in the population was one factor behind determining the criteria of selection. Diabetic patients selected were all diagnosed and aware that their condition needs daily actions and lifestyle modification to successfully manage their disease. The need to explore two different socioeconomic groups of patients, one in the NIDE in Cairo and another digitally literate sample (online) was an additional factor behind a purposive sample of diabetic patients from the mentioned population. 
Approvals were obtained from the Institutional Review Board (IRB), the Central Agency for Public Mobilization and Statistics (CAPMAS), and the NIDE Board. Printed surveys were distributed to patients in the (NIDE), where 258 respondents who signed a participation consent and completed the selfadministered survey. In addition, a bilingual digital version was distributed online to Facebook Arabic diabetes management groups and 150 completed the online survey (146 respondents answered the Arabic version, while only 4 respondents answered the English version) within the duration of the study. The full sample has reached $(n=408)$ totaling the offline sample in NIDE $(n=258)$ plus the online sample $(n=150)$ in two weeks.

\section{Results}

The first five research hypotheses were tested via the regression between the independent and dependent variables and the results were reported in Fig. 2 and Table 1. The regression supported all the seven hypotheses with highly significant positive relationships between the basic, communicative, and critical health literacy independent variables and the patient empowerment dependent variables for the full sample of 408 respondents.

\section{Table 1}

Correlation Coefficient Value $(R)$ between Independent \& Dependent variables

\section{in Research Hypotheses (Full sample $n=408)$ )}


Research Hypotheses

Correlation Coefficient

Value $(R)$ between

Independent \&

dependent variables

Full sample $(n=408)$

Hypothesis 1: The more the diabetic patient has sufficient information to manage diabetes, the more the diabetic patient can find meaningfulness in the actions they do on daily basis.

$R=0.598$

$\mathrm{p}<0.001$

Hypothesis 2: The higher the ability of the diabetic patient to find good quality health information on diabetes, the more the patient is self-

$\mathrm{R}=0.652$ determined and can choose between different ways of diabetes

$\mathrm{P}<0.001$ management.

Hypothesis 3: The more the diabetic patient understands health information on diabetes well enough to know what to do, the more selfefficacy he/she has in diabetes management.

Hypothesis 4: The higher the ability diabetic patients have to actively engage with healthcare providers, the more self-efficacy he/she has in diabetes management.

Hypothesis 5: The higher the diabetic patient actively manages his/her $\quad \mathrm{R}=0.641$ diabetes, the higher the positive impact on his/her diabetes management. $\quad P<0.001$

\section{Comparisons of online and offline samples}

The sixth hypothesis proposed that there is a significant difference in both the total health literacy and the patient empowerment between the online sample $(n=150)$ and the offline face-to-face NIDE sample (n-258). The independent variable pertaining to the method of responding to the survey was measured on a nominal scale, while the dependent variable (total health literacy) was measured by adding the mean scores of basic health literacy (three variables), the mean scores of communicative health literacy (one variable) and the mean score of critical health literacy (one variable).

The parametric statistic t-test was used to test if the mean health literacy score of the online sample $(\mathrm{n}=$ 150) was significantly higher than that of the face to face "offline NIDE" sample $(n=258)$. The results reported in Table 2 do not support the hypothesis as the level of health literacy is higher in the Face to Face 'offline' Sample (NIDE) $(n=258)$ than in the Online sample $(n=150)$. 


\section{Research Hypotheses}

\section{Correlation Coefficient \\ Value (R) between \\ Independent \& \\ dependent variables}

Full sample $(n=408)$
Hypothesis 1: The more the diabetic patient has sufficient information to manage diabetes, the more the diabetic patient can find meaningfulness in the actions they do on daily basis.

Hypothesis 2: The higher the ability of the diabetic patient to find good quality health information on diabetes, the more the patient is selfdetermined and can choose between different ways of diabetes management.

Hypothesis 3: The more the diabetic patient understands health information on diabetes well enough to know what to do, the more selfefficacy he/she has in diabetes management.

Hypothesis 4: The higher the ability diabetic patients have to actively engage with healthcare providers, the more self-efficacy he/she has in diabetes management.

Hypothesis 5: The higher the diabetic patient actively manages his/her diabetes, the higher the positive impact on his/her diabetes management.

$$
\begin{aligned}
& R=0.598 \\
& P<0.001 \\
& R=0.652 \\
& P<0.001
\end{aligned}
$$

$$
R=0.618
$$$$
\mathrm{P}<0.001
$$

$R=0.602$

$P<0.001$

$\mathrm{R}=0.641$

$P<0.001$

\section{Mean scores of Total Health Literacy and Health Literacy levels}

\section{in Online \& Face to Face "Offline" Samples.}

The seventh hypothesis proposed that diabetic patients who complete the online survey $(n=150)$ are more likely to have higher levels of patient empowerment than diabetic patients who respond to the offline self-administered survey $(n=258)$. Again the independent variable pertaining to the method of responding to the survey was measured on a nominal scale, while the dependent variable (total patient empowerment) was measured through adding the total mean score of the four variables constituting this macro-variable (total patient empowerment); meaningfulness, self-determination, self-efficacy, and impact. The parametric statistic t-test was used to test if the patient empowerment levels in the online sample $(n=150)$ is significantly more than that in the face to face "offline NIDE" sample $(n=258)$. Again, the total patient empowerment is higher in the Face to Face 'offline' sample (NIDE) ( $n=258)$ than in the online sample $(n=150)$, but not significantly (Table 3). Consequently, the t-test did not support the seventh hypothesis. 
Table 3

Mean scores of Total Patient Empowerment and Patient Empowerment variables in Online \& Face to Face "Offline" Samples)

\begin{tabular}{|c|c|c|c|}
\hline & $\begin{array}{l}\text { Online } \\
\text { sample (n } \\
=150)\end{array}$ & $\begin{array}{l}\text { Face to Face } \\
\text { 'offline' Sample } \\
\text { (NIDE) }(n=258)\end{array}$ & \multirow[t]{2}{*}{$\begin{array}{l}\text { Difference between online } \\
\text { and offline sample (T-test) } \\
\& \text { significance }\end{array}$} \\
\hline Health Literacy Variable & $\begin{array}{l}\text { Mean } \\
\text { score for } \\
\text { each } \\
\text { variable }\end{array}$ & $\begin{array}{l}\text { Mean score for } \\
\text { each variable }\end{array}$ & \\
\hline $\begin{array}{l}\text { 1. Basic health literacy's (Having } \\
\text { sufficient information to manage } \\
\text { my health) }\end{array}$ & 3.4 & 3.74 & $t=-3.943, p<0.001$ \\
\hline $\begin{array}{l}\text { 2. Basic health literacy's (Ability to } \\
\text { find good quality health } \\
\text { information) }\end{array}$ & 3.53 & 3.63 & $t=-1.249, p=0.21$ \\
\hline $\begin{array}{l}\text { 3. Basic health literacy's } \\
\text { (Understand health information well } \\
\text { enough to know what to do) }\end{array}$ & 3.6 & 3.76 & $t=-1.998, p=0.046$ \\
\hline Mean Score for Basic Health literacy & 3.5 & 3.7 & $t=-2.815, p=0.005$ \\
\hline $\begin{array}{l}\text { 4. Communicative health literacy's } \\
\text { (Ability to actively engage with } \\
\text { healthcare providers) }\end{array}$ & 3.29 & 3.86 & $t=-7.553, p<0.001$ \\
\hline $\begin{array}{l}\text { Mean Score for Communicative } \\
\text { Health literacy }\end{array}$ & 3.29 & 3.86 & $t=-7.553, p<0.001$ \\
\hline $\begin{array}{l}\text { 5. Critical health literacy's (Actively } \\
\text { managing my health) }\end{array}$ & 3.35 & 3.47 & $t=-1.513, p=0.13$ \\
\hline $\begin{array}{l}\text { Mean Score for Critical Health } \\
\text { literacy }\end{array}$ & 3.35 & 3.47 & $t=-1.513, p=0.13$ \\
\hline \multirow{2}{*}{$\begin{array}{l}\text { Mean Score for Total Health } \\
\text { Literacy }\end{array}$} & 3.32 & 3.67 & $t=-5.348, p<0.001$ \\
\hline & $\begin{array}{l}\text { Online } \\
\text { sample (n } \\
=150)\end{array}$ & $\begin{array}{l}\text { Face to Face } \\
\text { 'offline' Sample } \\
\text { (NIDE) }(n=258)\end{array}$ & \multirow[t]{2}{*}{$\begin{array}{l}\text { Difference between online } \\
\text { and offline sample (T-test) }\end{array}$} \\
\hline Patient Empowerment Variable & $\begin{array}{l}\text { Mean } \\
\text { score for } \\
\text { each } \\
\text { variable }\end{array}$ & $\begin{array}{l}\text { Mean score for } \\
\text { each variable }\end{array}$ & \\
\hline $\begin{array}{l}\text { Patient Empowerment's } \\
\text { Meaningfulness/Relevance }\end{array}$ & 3.71 & 3.8 & $t=-0.974, p=0.33$ \\
\hline $\begin{array}{l}\text { Patient Empowerment's Self- } \\
\text { Determination }\end{array}$ & 3.36 & 3.17 & $t=2.574, p=0.01$ \\
\hline Patient Empowerment's Self- & 3.42 & 4.01 & $t=-8.367, p<0.001$ \\
\hline
\end{tabular}


Patient Empowerment's Positive Impact

Mean Score for Total Patient Empowerment
3.67

3.54
3.68

3.67 $t=-0.097, p=0.92$

$t=-1.809, p=0.07$

\section{Discussion}

This paper aspired to serve as a first step in assessing the actual health literacy and patient empowerment levels of diabetic patients in Egypt. Health literacy is the main underlying linchpin in yielding patients who are effective self-managers of their health, showing high self-efficacy, and empowered. Diabetic patients studied in this research have shown high health literacy levels, and these levels seem to be significantly higher in the offline sample (NIDE) than the online sample. Diabetic patients studied in this research also showed that they have good empowerment levels.

Considering these health literacy levels and mapping the actual educational needs of diabetic patients, may help in planning and delivering customized dynamic patient education and support initiatives that meet the expectations of diabetic patients, eventually aiming at yielding well-educated patients who can effectively, manage their diabetes and positively influence their empowerment levels.

Utilizing online platforms in leveraging the health literacy and patient empowerment levels holds a great promise in reshaping the educational and patient support initiatives; however, from the insights of the studied diabetic patients, there seems to be a gap where diabetic patients seek to find an online 'go-to' hub to learn more on diabetes. And the available online initiatives may offer generic content complicated with medical terms, which need to be evaluated in future research.

Creating a social network model that utilizes the raw data and insights shared by patients on daily basis, analyzing raw information into actionable advice is still a bridge that needs to be crossed in diabetic patients' healthcare. Extending and utilizing the healthcare professional's trust in social media platforms is assumed to leverage the health literacy and patient empowerment levels, especially in terms of guidance and support on how to find and interpret online sources of information. This model may fill the gap of not having a trustworthy 'go-to' online hub for diabetic patients.

Further research can include replicating this research to compare the health literacy and patient empowerment levels in diabetic patients from different socio-economic classes, patients with and without medical backgrounds, and to extend the analysis and understanding of the diabetic patients' profiles. Furthermore, to utilize the "health literacy questionnaire (HLQ) and assess diabetic patient profiles individually in focus groups in order to grasp deeper insights on personalized diabetic patient profiles. Future research can also focus on digital literacy and the digital health literacy assessment of diabetic patients in order to determine the requirements for online patient engagement programs and platforms, as well as content analysis for social support groups on Facebook and social media hubs. 


\section{Conclusion}

The main shortcoming of public healthcare communication campaigns is that it mostly renders a oneway informative communication that may influence the knowledge of the learner through observation but misses the core objective of the theory which eliciting a change in health-related behavior with social endorsements. Effective planning is then necessary to include all three aspects, to avoid failure in addressing the rigid (socio-cognitive) factors (learner, behavior, and environment).

Commercialism is also another challenge facing the implementation of social cognitive theory in particular and other healthcare educational initiatives aiming at changing behaviors campaigns at large, when the commercial intent is the driving force behind the healthcare communication the planned communication strategy may not address all the socio-cognitive factors (learner, behavior, environment), consequently missing the behavioral change. One of the pitfalls of having the commercial intent as the driving force behind healthcare communication is that the developed measures of the campaign success are individualistic or commercial rather than measures of socio-cognitive factors fundamental to the health problem; such as sales revenues, increased doctor visits, improved share of voice instead of proper management or changed health behavior measures.

Several managerial implications can be gleaned from this research. First, successful healthcare communication strategies should include the allocation of major shares of the campaign resources and dedicated implementation techniques for the socio-cognitive factors. This could be critical to the success of health communication initiatives in identifying the health problem and devising the content strategy and more. Second, it is essential to develop closed-loop communication and feedback cycles that include measures to evaluate the perception of information and its interpretation into actionable advice. Third, the translation of information into practices plus developing follow-up measures to support the targeted patients in case of setbacks or facing difficulties is crucial. Finally, developing healthcare communication programs by means of social cognition endorsed by popular social media platforms and networks to redirect the social efforts to embrace the health-related change in behavior.

\section{Abbreviations}

CAPMAS Central Authority for Population Mobilization And Statistics

eHLF e-health literacy framework

HLQ Health Literacy Questionnaire

IRB Institutional Review Board

NIDE National Institute of Diabetes and Endocrinology

Ophelia Optimizing Health Literacy and Access

Page 15/19 


\section{Declarations}

- Ethics approval and consent to participate

- All the research procedures including the Arabic and English questionnaires used had the respondents consent and were approved by the Institutional Review Board of The American University in Cairo (Case \# 2017-2018-065), the Board of National Institute of Diabetes and Endocrinology in Cairo, and CAPMAS.

- Consent for publication

- Not applicable

- Availability of data and material

- All data is available upon request.

- Competing interests

- All authors do not have competing interests

- Funding

- No funding was received from any third party

- Authors' contributions

- SF developed the questionnaires, collected the data, and prepared the first draft of this paper

- AT developed the research point, contributed to the analysis of the data, supervised and contributed to the first and final drafts, and served as the corresponding author responsible for the submission.

- IS prepared the final draft and reviewed the paper for logic and linguistic accuracy.

- All authors have read and approved the manuscript

- Acknowledgments

- None.

\section{References}

1. Abueleinen KGI, El-Mekawey H, Saif YS, Khafagy A, Rizk HI, Eltahlawy EM. Sociodemographic factors responsible for blindness in diabetic Egyptian patients. Clinical ophthalmology (Auckland NZ). 2011;5:1593. 
2. Anderson RM, Funnell MM. Patient empowerment: myths and misconceptions. Patient Educ Couns. 2010;79(3):277-82.

3. Bandura A. Health promotion from the perspective of social cognitive theory. Psychology health. 1998;13(4):623-49.

4. Bandura A. Health promotion by social cognitive means. Health education behavior. 2004;31(2):143-64.

5. Batterham RW, Hawkins M, Collins PA, Buchbinder R, Osborne RH. Health literacy: applying current concepts to improve health services and reduce health inequalities. Public Health. 2016;132:3-12.

6. Baudrant M, Allenet B, Le Tallec C, Grangeat M, Calop J. Educating diabetic children: integrating representations by children aged 7 to 11 and their parents. Pharmacy world science. 2007;29(6):699-703.

7. Berkman N, Davis TC, McCormack L. Health Literacy: What Is It? Journal of Health Communication. 2010;15(sup2):9-19. DOI:10.1080/10810730.2010.499985.

8. Bryant J, Oliver MB, (2009) eds. Media effects: Advances in theory and research. Routledge.

9. Camerini L, Schulz PJ, Nakamoto K. Differential effects of health knowledge and health empowerment over patients' self-management and health outcomes: a cross-sectional evaluation. Patient Educ Couns. 2012;89(2):337-44.

10. Friis K, Lasgaard M, Osborne RH, Maindal HT. Gaps in understanding health and engagement with healthcare providers across common long-term conditions: a population survey of health literacy in 29473 Danish citizens. BMJ Open. 2016;6(1):e009627.

11. Gordon J. Educating the patient: challenges and opportunities with current technology. Nurs Clin North Am. 2011;46(3):341-50.

12. International Diabetes Federation. (2019). IDF diabetes atlas ninth edition 2019.

13. Lubi k. The adaptation of everyday practices in the adoption of chronic illness. Health. 2019;23(3):325-43.

14. Norgaard O, Furstrand D, Klokker L, Karnoe A, Batterham R, Kayser L, Osborne RH. The e-health literacy framework: a conceptual framework for characterizing e-health users and their interaction with e-health systems. Knowledge Management E-Learning: An International Journal (KM\&EL). 2015;7(4):522-40.

15. Nutbeam D. Health literacy as a public health goal: a challenge for contemporary health education and communication strategies into the 21st century. Health Promot Int. 2000;15(3):259-67.

16. Osborne RH, Batterham RW, Elsworth GR, Hawkins M, Buchbinder R. The grounded psychometric development and initial validation of the Health Literacy Questionnaire (HLQ). BMC Public Health. 2013;13(1):658.

17. Osborne RH, Beauchamp A, Batterham R. Health literacy: a concept with the potential to greatly impact the infectious diseases field. International Journal of Infectious Diseases. 2016;43:101-2. 
18. Sarkar U, Karter AJ, Liu JL, Adler NE, Nguyen R, López A, Schillinger D. The Literacy Divide: Health Literacy and the Use of an Internet-Based Patient Portal in an Integrated Health System-Results from the Diabetes Study of Northern California (DISTANCE). Journal of Health Communication. 2010;15(sup2):183-96. DOI:10.1080/10810730.2010.499988.

19. Schulz PJ, Nakamoto K. Health literacy and patient empowerment in health communication: the importance of separating conjoined twins. Patient Educ Couns. 2013a;90(1):4-11.

20. Schulz PJ, Nakamoto K. Patient behavior and the benefits of artificial intelligence: the perils of "dangerous" literacy and illusory patient empowerment. Patient Educ Couns. 2013b;92(2):223-8.

\section{Figures}

Independent

Health Literacy

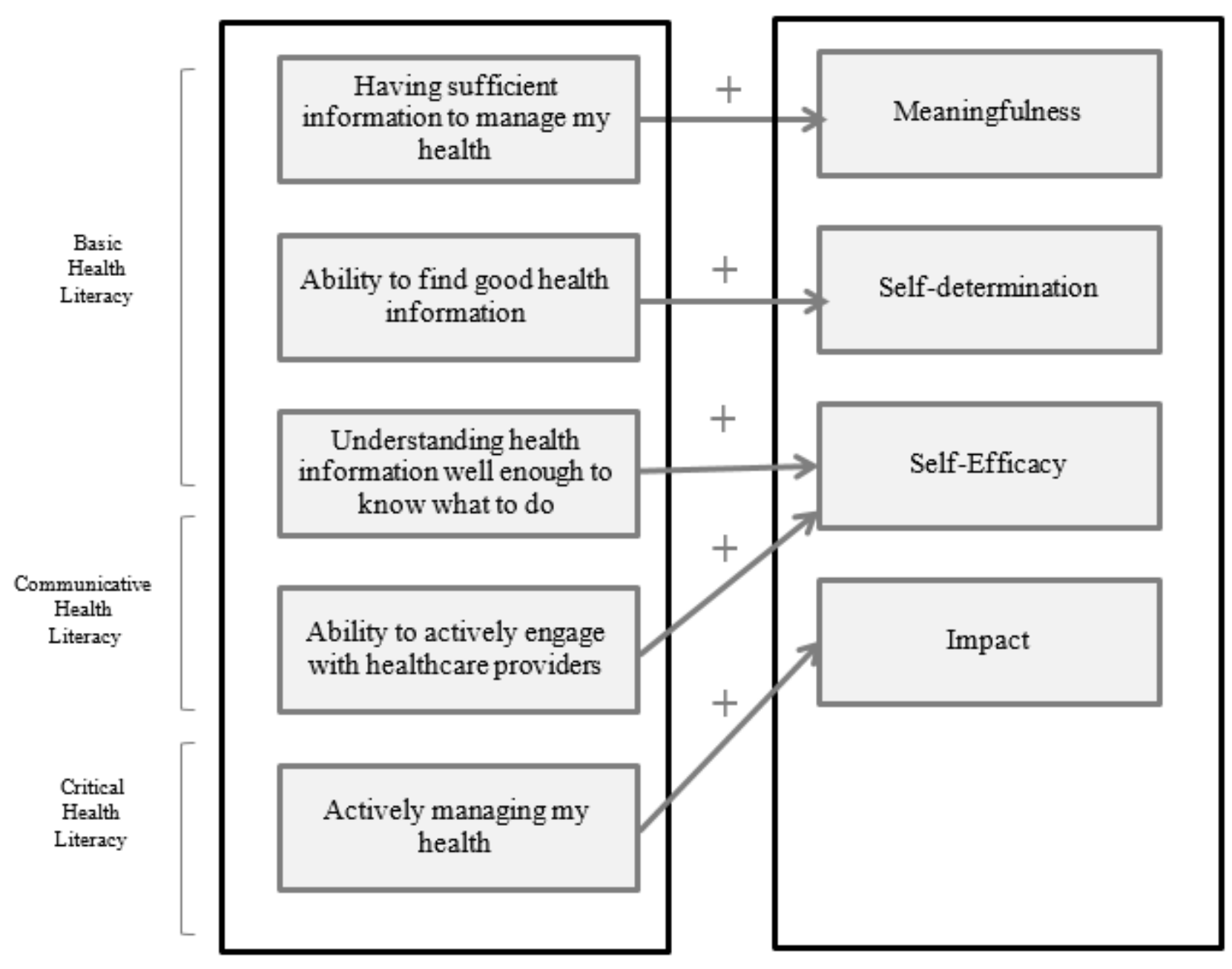

Figure 1

Research conceptual model and hypothesized relations between the independent and dependent variables 
Independent Variable

Health Literacy

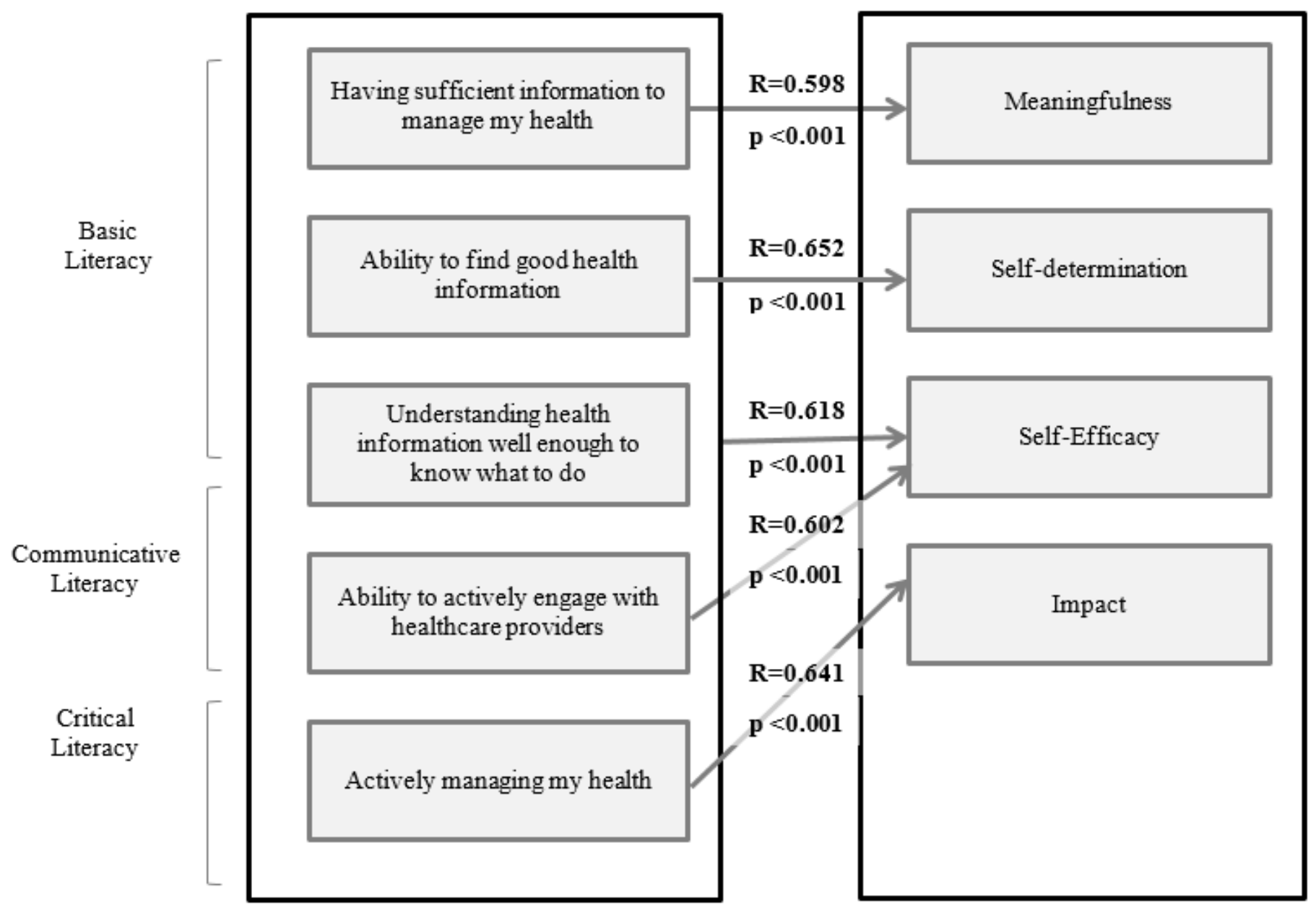

\section{Figure 2}

Research conceptual model and the Correlation Coefficient $(R)$ values and significance in the hypothetical relations between the independent variables and the dependent variables 